\title{
Espacios domésticos de resistencia: la cama en el arte de los siglos XX y XXI desde una perspectiva de género ${ }^{2}$
}

\author{
Domestic Spaces Of Resistance: The Bed In Art Of 20th \\ and 21st Centuries From A Gender Perspective
}

\begin{abstract}
RESUMEN
La cama, en tanto soporte y alegoría del cuerpo, alude a nuestra dependencia humana originaria, siendo su función central en la definición del ámbito doméstico. Este enser, por tanto, problematiza la cuestión de la intimidad y adquiere una marcada connotación de género pues dicho ámbito tradicionalmente ha sido reconocido como femenino. Lo doméstico es la esfera del descanso y la comodidad, pero también del trabajo rutinario despreciado, a cuya visibilización ha contribuido la labor deconstructiva del arte y la crítica feminista. Por ello, desde la Estética y Teoría de las Artes analizaremos las principales exposiciones y obras de mujeres artistas que se han dirigido de forma crítica a la cama desde diversos medios. Nuestra genealogía abarcará principalmente los siglos xx y xxI para valorar la actualidad de dicho mueble como límite posibilitante, como un escenario a menudo opresor y estetizante pero a la vez presto a la subversión y resignificación.
\end{abstract}

Palabras clave: cama, arte contemporáneo, género, resistencia, espacio doméstico.

\section{Abstract}

The bed, as support and allegory of the body, alludes to our original human dependence, having a central function in the definition of the domestic sphere. Hence, this piece of furniture makes an issue on the question of intimacy and acquires a marked gender connotation since this sphere has traditionally been recognized as feminine. The domestic is the place of rest and comfort, but also of despised routine work, to whose visibility the deconstructive task of art and feminist criticism has contributed. Therefore, from the Aesthetics and Theory of the Arts, we will analyze the main exhibitions and the artworks of women artists who have addressed the bed critically from different media. Our genealogy will mainly cover the $20^{\text {th }}$ and $21^{\text {st }}$ centuries to value the relevance of said furniture as an enabling limit -as an often oppressive and aestheticizing scenario, but at the same time prone to subversion and resignification.

Keywords: bed, contemporary art, gender, resistance, domestic space.

\section{SUMARIO}

1.- Introducción: la cama en tanto alegoría del cuerpo. 2. Mujer y lecho en la Historia de la Pintura (siglos XVI-XIX). 3.- la subversión del espacio doméstico. posmodernidad y crítica feminista (siglos XX-XXI). 3.1.- La feminización de la cama como escenario de subordinación y enfermedad: respuestas desde la fotografía, el vídeo y la instalación. 3.2.- La cama intervenida desde las artes menores y el ready made: sátira, ironía y poéticas intimistas y procesuales. 3.3.- La cama a la intemperie para un arte expandido al albor del cambio de milenio: precariedad, violencia, vigilancia. 4.- Conclusiones. 5.- Bibliografía.

1 Universidad de Castilla-La Mancha, josel.panea@uclm.es

2 Este artículo ha sido posible gracias a la obtención de un Contrato Post-doctoral (por lectura de Tesis, $4^{\circ}$ año) del Plan Propio de la UCLM (Ref.: 2016/14100) en el marco del Proyecto MICIU de I+D+i “EShID: Estéticas híbridas de la imagen en movimiento. Videoarte español y dinámicas identitarias en el mapa global" (2019-2021, Ref: PGC2018-095875-B-I00). 


\section{1.- Introducción: la cama en tanto alegoría del cuerpo}

El entorno doméstico ha devenido tropo frecuente en el arte al visibilizar la vida cotidiana, siendo esta, «de todas las esferas de la realidad, la que más se presta a la extrañación» (Heller, 1985: 65), mantiene Agnes Heller. Si el propio habitar se define así por la regularidad que implica la cotidianidad, el arte en este sentido ha contribuido a la resignificación de aquellos espacios que nos resultan familiares, aportándoles otra mirada (Borzello, 2006; Pollock, 2013). Pero lo doméstico no solo es la residencia física, sino que se construye a nivel relacional, implicando también a las funciones y tramas que dentro de la casa se suceden (Heidegger, 2015). Todo hogar, aunque precisa de unos límites, se forja en las relaciones que estos convocan: requiere de un marco físico pero a la vez de las interacciones desarrolladas en su interior, las cuales lo acotan y definen (Ørskou, 2003: 18). Es por ello que no hay elección: todos/as estamos condenados/as a un habitar practicado en la elección constante pues precisamos de un lugar donde vivir y cobijarnos (Sartre, 2006: 140). Además, en él se personaliza la existencia a través de un hacer constante tan personal como político donde los contornos de la intimidad se desdibujan (Sibilia, 2014: 42). Por tanto, la creación queda intrínsecamente relacionada al ámbito doméstico, muy presente en el arte contemporáneo (Pallasmaa, 2016: 36) a causa de la creciente deslocalización de la idea de hogar, no solo por los avances en las telecomunicaciones sino por la transformación del trabajo a escala global (Sennett, 1998).

Asumir esta condición permite un habitar entregado y consciente, que tiene en cuenta la importancia de nuestras relaciones en el ámbito privado para un desempeño más ético en el afuera, apunta Gaston Bachelard (2006: 31). Si la casa es asociada al refugio y la feminidad, es necesario iluminar cómo todo lo que se desarrolla bajo su techo suele ser menoscabado en relación a lo público, próximo al falogocentrismo que Derrida evidenciaba (2019), lo que está más allá de sus paredes (Pérez, 2010: 21). Esta toma de conciencia daría lugar así a la desarticulación de las lógicas imperantes en lo doméstico, que pasan por alto sus violencias por cotidianas, espontáneas, soterradas (Heller, 1985: 64). En este sentido, dentro de la casa, el estadio de mayor intimidad lo alberga el dormitorio, presidido por uno de los muebles más asociados en la Historia del Arte a lo femenino: la cama. La cama, cuyas medidas se adaptan al cuerpo -desde la cuna a la cama de matrimonio- suele devenir tabla de salvación al implicar una recuperación y oportunidad para estar con uno/a mismo/a, y en el arte ha sido representada para problematizar las tensiones entre a) descanso y trabajo, b) sexualidad y erotismo y c) salud y enfermedad (Colomina, 2014: 22; Codognato, 2015: 23). Aquí nos centraremos en el segundo enunciado por cómo cataliza la expresión de los roles de género y por su gran presencia, con frecuencia romantizada, en los imaginarios colectivos, lo cual apoyándonos en la crucial presencia del arte feminista urge subvertir (Butler, 2007: 167). 


\section{2.- Mujer y lecho en la Historia de la Pintura (siglos XVI-XIX)}

En la Historia del Arte occidental es principalmente desde el Renacimiento hasta finales del siglo XVIII cuando se asiste a una creciente vinculación entre los conceptos de mujer y lecho, teniendo como ejemplos paradigmáticos las habitaciones de la Venus de Urbino (1538) de Tiziano o La visite du médicin de Jan Steen (1665), donde el cuerpo femenino es protagonista. Si bien es cierto que dicho cuerpo es representado constantemente en la tradición pictórica desde la Antigüedad, su asociación al mueble que nos convoca comienza a tener cabida conforme este se populariza entre las clases medias (Perrot, 2009: 84) y se empieza a asociar el concepto de intimidad al ámbito de la casa, una invención burguesa de los siglos XV y XVI (Alpers, 1987; Rybczynski, 1989; Todorov, 2013) que tendrá su mayor apogeo en la sociedad victoriana del XIX (Sibilia, 2014). Además, como en su volumen At home: an anthropology of domestic space (2006), Irene Cieraad expresa: «el proceso de domesticación de la mujer comenzó (...) en las clases acomodadas, y solo lentamente afectaría a las clases más bajas» (Cieraad, 2006: 51), tanto por su acceso a estudios y oficios de interior como la pintura, como por ser la burguesía la inventora de la «domesticidad» (Borzello, 2006: 56-58). Por consiguiente, al representar la inmediatez y particularidad de la experiencia cotidiana, los interiores -principalmente los más majestuosos- han estado muy presentes en el arte (Pollock, 2013: 120; Borzello, 2006: 18-19), en concreto durante el siglo de oro holandés, donde los temas cotidianos se superponen a la pintura de historia (Rybczynski, 1989: 61).

El filósofo Tzvetan Todorov apunta el marcado carácter existencial de este viraje (2013: 17), donde las actividades rutinarias adquieren la misma dignidad de «figurar en el centro de un cuadro como la coronación de un rey» (73). Y las mujeres, aunque estén en casa, suelen aparecer socializando, entreteniéndose, escribiendo, preparándose para una salida (89) o leyendo (29), a pesar de que la lectura sería condenada por parte de la Iglesia, sobre todo si era en la cama por la noche al despertar la imaginación de la mujer y evadirla de la morada (Perrot 2009: 117). No obstante, según Svetlana Alpers (1987: 28), la pintura de género holandesa no es prescriptiva ni moralista, sino descriptiva (30), favoreciendo la interpretación del/ la espectador/a. Dicha interpretación es suscitada con un despliegue de elementos irónicos, sobre todo acerca del tema de la enfermedad, frecuentemente asociada a la feminidad (Pérez Gil, 2016) como en las pinturas de Jan Steen sobre las visitas médicas (Brown, 1984: 98-94). Sin embargo, pese a la ausencia de mujeres pintoras en este movimiento, al menos este presagió un cambio en los modos de entender lo cotidiano (Todorov, 2013: 48 y 89; Panea, 2017), inspirando «un despliegue de tradiciones e iconografías» (2013: 16), aun siendo considerado durante mucho tiempo un tema menor, banal o poco edificante (Borzello, 2006: 6).

Dentro de este interior, la cama resulta «un lugar esencial, cuasi metafísico» (Perrot, 2009: 438), según Georges Perec, «un espacio rectangular, más largo que ancho, en el cual, o sobre el cual, uno se acuesta normalmente en sentido longitudinal» y se concibe «para el descanso nocturno de una o dos personas, pero no más» (Perec, 
2007: 37). Destacamos este «no más» puesto que entonces el lecho desde su origen apela a la dualidad, otorgando una condición colectiva al dormir. Nuestro mueble tendría tanta importancia que el siglo XVII sería conocido como «el gran siglo de la cama» ya que desde Versalles se promovieron numerosos diseños en la época, aunque para las clases acomodadas (Perrot, 2009: 84). Los somieres de muelles, hacia 1840, «producto de la revolución industrial» reemplazarían «el anterior sistema de colchones apilados» $\mathrm{y}$ «el edredón de plumas fue desterrando, poco a poco, a las sábanas» (85). La cama proliferó en «la cultura occidental» y «la individualización del sueño», uno de los hitos de «la Italia del Quattrocento» (99) se hizo realidad. No obstante, en el arte, con su institucionalización durante el siglo siguiente a través de las Academias, la pintura de historia relegará estos temas (Borzello, 2006: 1819). El contrapunto lo supondría La maja desnuda (1797-1800) de Goya, la primera imagen en la Historia del Arte que represente a una mujer recostada en la cama, desnuda y mostrando su vello púbico, así como Manet en la Olympia (1863), donde el dormitorio aparecerá como el escenario de la prostituta causando gran escándalo en el salón de 1865 (Pollock, 2013: 116). Al igual que El origen del mundo de Courbet (1866), pintura que durante un siglo estuvo sin ver la luz (Clayson, 1991: 2). En la mayoría de ellas, a pesar de su aparente crítica, la mujer está supeditada a la mirada masculina (39), mirada que forja las actitudes y predisposiciones corporales en el ámbito de lo público, así «el cuerpo es la fase principal en lo que esta división deja su rostro», añade Nelly Richard (1986: 65).

Otra cuestión a la que resulta inevitable atender en cuanto a la representación del lecho es la prostitución. En Painted love: Prostitution in French Art of the Impressionist Era, Hollis Clayson revisa las pinturas clásicas del Impresionismo (Clayson, 1991: 26), donde el lecho se politiza, pues no hay reposo sin custodia. La labor de asistencia a la que las mujeres han sido abocadas históricamente adquirirá un matiz evidente en las pinturas de Edgar Degas, como Repose (1879-1880), cuyas prostitutas «apelan a una existencia en la cual el sí mismo y el cuerpo se han convertido en lo mismo y la sexualidad de la mujer se ha perdido en el mundo de los intercambios» (Clayson 1991: 39). Un rápido examen por este periodo muestra cómo la mujer aparece instrumentalizada, en un escenario forzado presta a las solicitudes de la mirada masculina heterosexual. En este sentido, a menudo para cubrir dichos deseos, prostitución y lesbianismo han convergido, siendo un tema principal en la obra de Toulouse-Lautrec (51). Ya en Así habló Zaratustra (1883) Nietzsche escribía que «el hombre debe ser educado para la guerra, y la mujer, para solaz [reposo] del guerrero» (1976: 64). Un concepto, el de reposo, solaz o descanso, que atiende al cuerpo femenino como una promesa de recreo y cobijo, y por tanto políticamente connotado. En contraposición, artistas coetáneas a estos pintores como Mary Cassatt, Mary Ellen Best o Marguerite Gérard no aluden ni al voyeurismo ni al coqueteo de sus homólogos masculinos (Borzello, 2006: 1994). Tampoco aparecen las mujeres en poses sugerentes, sino que, cuando reposan sobre el diván, el sofá o la cama, remiten al interés por la lectura y la política, como en Reading Le Figaro (1878) de Cassatt, y por la divulgación o narración oral, como Mrs Cassatt Reading to her Grandchildren (1880). Breakfast in bed (1897) [Imagen 1] será también otro ejemplo donde 
aparece esta visión de la cama asociada en este caso a la maternidad, más que con el romanticismo ocasional de la distancia paterna, con la incertidumbre cotidiana de su progenitora.

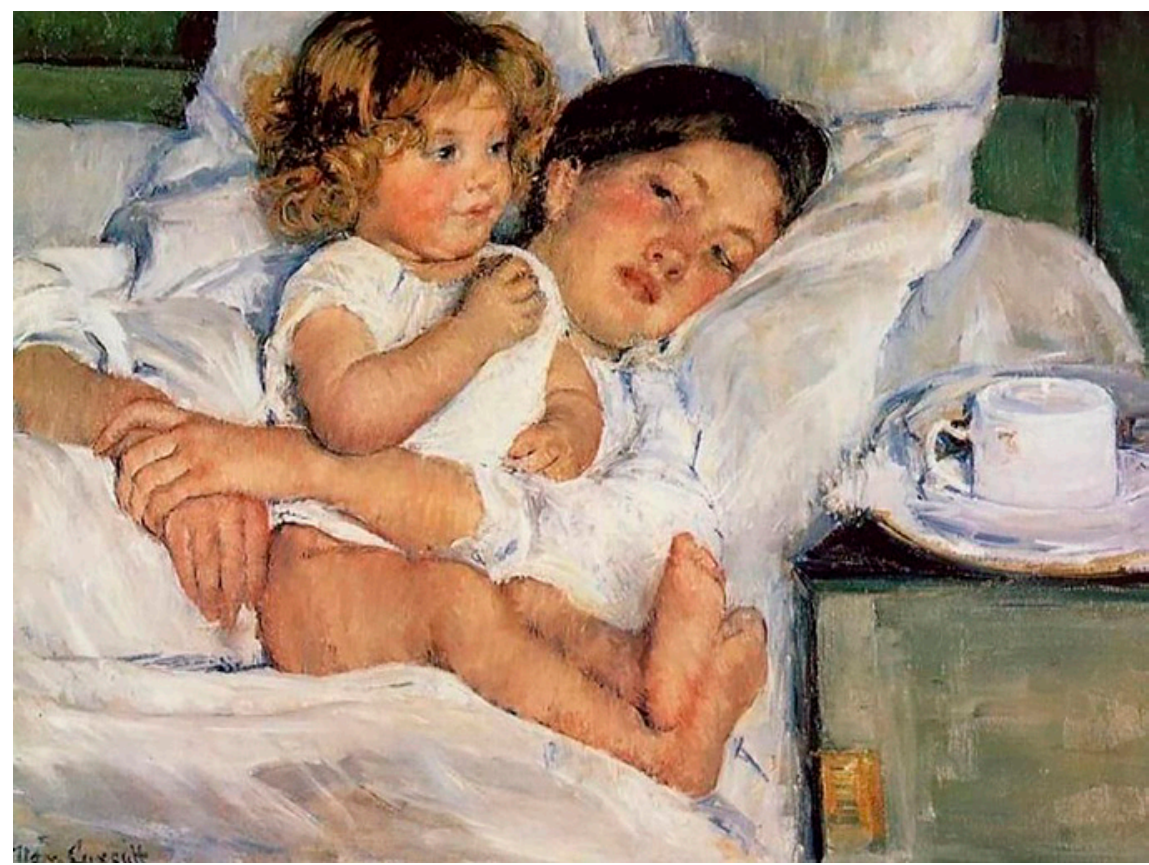

Imagen 1. Mary Cassatt, Breakfast in bed, 1897. Óleo sobre lienzo. The Huntington Library, Art Museum and Botanical Gardens. Fuente: https://www.marycassatt.org/Breakfast-In-Bed.html

Por otro lado, el dormitorio adquirirá también protagonismo debido al abaratamiento del precio de la cama de matrimonio, «el territorio real y simbólico de la familia», compartido por ambos cónyuges: «en el pasado, la cama nupcial no solo representó el símbolo de una nueva unidad familiar sino que era también uno de los bienes más preciados que se podían poseer» (Codognato, 2015: 18). La cama y el acto de dormir también se vincularán al momento en referencia a los avances médicos de la Modernidad con la proliferación de los hospitales. En Historia de las alcobas, apunta Michelle Perrot que «el médico sustituyó al cura» (2009: 327) y con el desarrollo de la medicina moderna en las pinturas de interiores proliferará la figura del médico (Vigué y Ricketts, 2007: 199) en contraposición a la de las monjas (199), debatiendo así la relación entre espiritualidad y ciencia (199). Esta dualidad, según Jana Leo, suscita la pregunta acerca de «la falta de espacio femenino» tanto a nivel de oportunidades laborales como espaciales, imbricándose ambas en línea con «los estudios sobre la ansiedad y la sexualidad» acerca de la feminidad (Leo, 2004: 288). Incluso bien entrado el siglo XX la erotización de la mujer en el lecho desde la mirada masculina ha sido constante. Fetichismo que cabe destacar en Pierre Bonnard con Nude lying on a white and blue checked background (1909), Edward 
Hopper, A woman in the sun (1961) -probablemente el artista más conocido al respecto al representar con frecuencia a mujeres solitarias desnudas en sus cuartos-, Salvador Dalí, que de hecho titulará a uno de sus dibujos Le repos du guerrier (1969), y Lucian Freud, en su sexualmente explícito Naked girl with egg, de 1980-1981 (Hughes, 2003: 64), donde hay una marcada insistencia en la carnalidad de los cuerpos de las mujeres. Coetánea de algunos de ellos, Frida Kahlo sería el ejemplo más conocido en cuanto a la relación entre enfermedad y feminidad (Pérez Gil, 2016: 275-276). No obstante, aquí nos interesa cómo su dependencia se reafirma como oportunidad creativa: los largos periodos de la artista en ese forzado reposo la llevaron a representar su lecho en pinturas como La cama volando, Henry Ford Hospital (1932) [Imagen 2], donde presenciamos «el estigma de la cama unida al cuerpo» (387). Sin dejar de lado su problemática subordinación a Diego Rivera, destacamos, empero, que se trataba de una pintura pionera sobre la mujer en la cama realizada por una mujer en la cama.

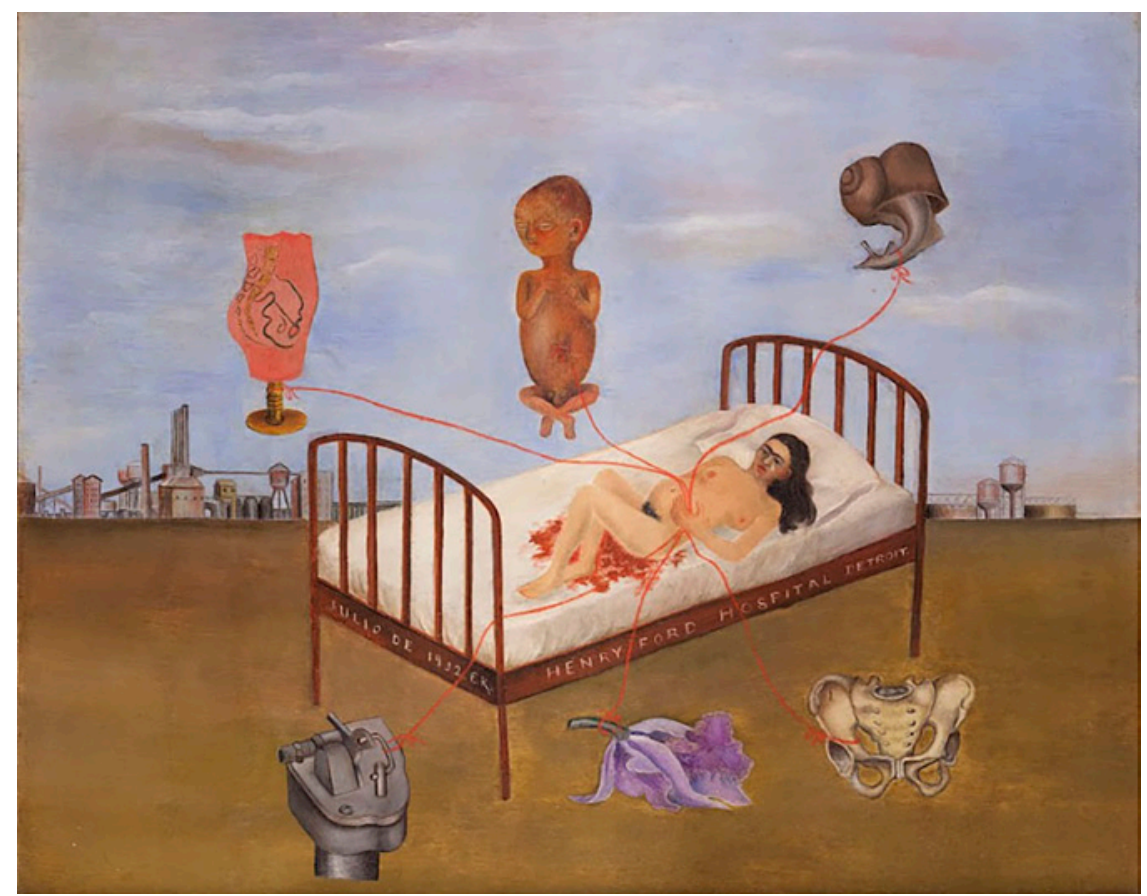

Imagen 2. Frida Kahlo, La cama volando, Henry Ford Hospital, 1932. Óleo sobre lámina metálica. Colección privada. Fuente: https://www.fridakahlo.org/henry-ford-hospital.jsp

\section{3.- La subversión del espacio doméstico. Posmodernidad y crítica feminista (Si-} glos $\mathrm{XX}-\mathrm{x} \mathrm{xI})$

Ya en el siglo $x x$ resulta crucial destacar una de las mayores transformaciones del entorno doméstico: el regreso de los soldados a casa tras la II Guerra Mundial 
y la incorporación de la mujer al ámbito laboral. Si hasta entonces las «esferas» de lo público y lo privado habían estado plenamente delimitadas en base a una estricta división de género (Preciado, 2010: 35), a causa de la contienda «la célula familiar» se dislocaría "por el alistamiento masivo de los hombres en el ejército» y la integración de las mujeres en el mercado de trabajo (35). A esto habría que sumar la irrupción de la máquina en las tareas del hogar, agilizando el día a día, pero a la vez exigiendo mayor eficacia del trabajo femenino (Bourdieu, 2000: 80). A pesar del ingreso femenino en el mercado laboral, su trabajo seguía siendo "una prolongación de las funciones domésticas: enseñanza, cuidado, servicio», ella aún debía ocuparse «a unas funciones subordinadas de asistencia» (117) como el secretariado (Sennett, 1998: 146), mientras el hombre tenía «el monopolio de la manipulación (...) de las máquinas» (Bourdieu, 2000: 117). El debate entre trabajo doméstico y asalariado resulta capital, siendo denunciado por Betty Friedan en La mística de la feminidad (1963), «el manifiesto de la «esposa suburbana» que lucha por liberarse del régimen de encierro de la casa unifamiliar que caracteriza a la sociedad norteamericana durante la guerra fría» (Preciado, 2010: 48). Por ello, el objetivo era «destruir la figura mítica tradicional del «ama de casa» y el «ángel del hogar»» (48-49).

En el plano artístico esta toma de conciencia coincidió con la revolución posmoderna. Si el acto de dormir fue uno de los motivos principales del Surrealismo unido a los traumas, la sexualidad y el inconsciente, en el arte posmoderno estos alcanzan una dimensión más específica que sitúa y localiza la cuestión de la autoría (Ardenne, 2000: 9-14) al emerger, inevitablemente cuando se habla de cuestionamiento, el tema de la identidad (Martínez-Collado, 2017: 23). Las prácticas artísticas autobiográficas (Sanjuán, 2020: 58), los feminismos y la crítica cultural fueron cruciales para la deconstrucción simbólica de los imaginarios de la casa (Serota y Ross, 2000: 25), a lo que Gill Perry en Playing at Home: The House in Contemporary Art responde afirmando que este es el espacio por excelencia para la redefinición de la subjetividad (Perry, 2013: 24) y adquiere un gran "potencial» al evocar «muchos aspectos de la vida personal y familiar -desde el nacimiento hasta la muerte-», con lo cual el dormitorio, y «más específicamente la cama, ha entrado en la iconografía de muchos/as artistas» (38). Pero la casa es también un espacio laboral, de producción constante, como arguye Jennifer Johung en su libro Replacing Home, al albergar nuestro impulso primigenio constructivo (Johung, 2012: 21). Es sobre todo a partir de los años noventa del siglo pasado que a estas cuestiones se suma la proliferación de exposiciones temáticas como espacio interdisciplinar para la generación de conocimiento (Obrist, 2010), y es el tiempo del auge de la instalación artística como punto de encuentro multimedial, integrando las obras en un todo, de la que ya Rosalind Krauss sentó las bases con su concepto de «campo expandido» (Krauss, 2002: 60). Esta modalidad artística adquiere especial sintonía con lo doméstico al compartir su aspecto inmersivo pues el espectador forma parte de la pieza al igual que el habitante de los muros de su morada (Archer, 1994: 29). Esto nos retrotrae al tema del cuerpo (30) pues la obra expandida se muestra como espacio para habitar, añade la historiadora Imogen Racz (2015: 13). Por ello el llamado arte micropolítico 
emerge aquí para pasar de una visión «predictiva» a una entrega a la inmediatez cotidiana (Ardenne, 2000: 9).

A finales de los noventa y a partir de los años 2000 comienzan a proliferar las muestras internacionales que albergan la cuestión del habitar desde este punto de vista, muchas centradas en el ámbito del dormitorio y la cama. Destacamos $\mathrm{La}$ casa, il corpo, il cuore. Konstruktion der Identitaten (comisario Lórand Hegyi, Museum Moderner Kunst Stiftung Luwdig, Viena, 1999) y Quotidiana. The Continuity of the Everyday in 20th Century Art (comisarios Nicolas Serota y David A. Ross, Castello di Rivoli, Museo d'Art Contemporanea, Turín, 2000), probablemente las más conocidas tanto debido al número de artistas participantes como al prestigio de los centros donde se celebraron. Otras exposiciones más locales, como Home sweet home (comisaria Gitte Ørskou, Aarhus Kunstmuseum, Aarhus, 2003), y A piel de cama. Miradas sobre un espacio cotidiano (comisaria Maite Ibáñez, Sala Parpalló, Valencia, 2010) son importantes al enfocar de una manera muy concreta el tema, y por último las recientes Schlaflos / Sleepless. The Bed in History and Art (comisario Mario Codognato, Belvedere21, Viena, 2015) o No Place Like Home (comisaria Adina Kamien-Kazhdan, The Israel Museum, Jerusalén, 2017) revelan las tensiones entre las categorías de lo público y lo privado (Colomina, 2014: 19), haciendo del entorno doméstico un repositorio de las transformaciones de la intimidad de nuestra era globalizada, mostrando la actualidad de la temática.

\section{1.- La feminización de la cama como escenario de subordinación y enferme- dad: respuestas desde la fotografía, el vídeo y la instalación}

Una de las principales respuestas que han dado las artistas feministas a la asociación entre la mujer y el espacio de la cama ha sido desde la fotografía y los así denominados nuevos medios para subvertir las disciplinas canónicas de la Historia del Arte como la pintura o la escultura. Una de las pioneras en el arte feminista al albor de la posmodernidad, tanto por la temática como por los medios empleados es Martha Rosler (Brooklyn, 1943). En plena Guerra de Vietnam, en sus fotomontajes expresa el impacto de las atrocidades del momento en la esfera doméstica, concretamente acerca del fenómeno conocido como «fatiga de combate» (Giddens, 1992: 98) donde los combatientes vencedores sufrieron el Shell Shock: «Los soldados que volvían de Vietnam sufrían desorientación psicológica, embotamiento de los sentimientos e incapacidad de establecer relaciones con personas distintas de sus antiguos camaradas de armas» (98-99). Como vemos, siguiendo la célebre proclama feminista «Lo personal es político», lo bélico irrumpe en la casa rompiendo su noción idílica de espacio protector. Dentro de la serie House Beautiful: Bringing the war home (1967-1972) (de la que llevó a cabo una continuación en 2006), trazando una conexión entre belleza y descanso destacamos Beauty Rest [Imagen 3], donde contrapone en el centro de la composición la imagen en color de «un colchón nuevo» e impoluto, pero en el interior de una habitación destrozada por una catástrofe, en blanco y negro, y en la que en la pared del fondo «cuelga un crucifijo» (Aliaga, 
2009: 30). Sobre la cama, un matrimonio heterosexual y un niño están tumbados, el padre juega con un avión de juguete con su hijo «inculcándole así normas y fascinación bélicas», mientras que «la madre lee» (31).

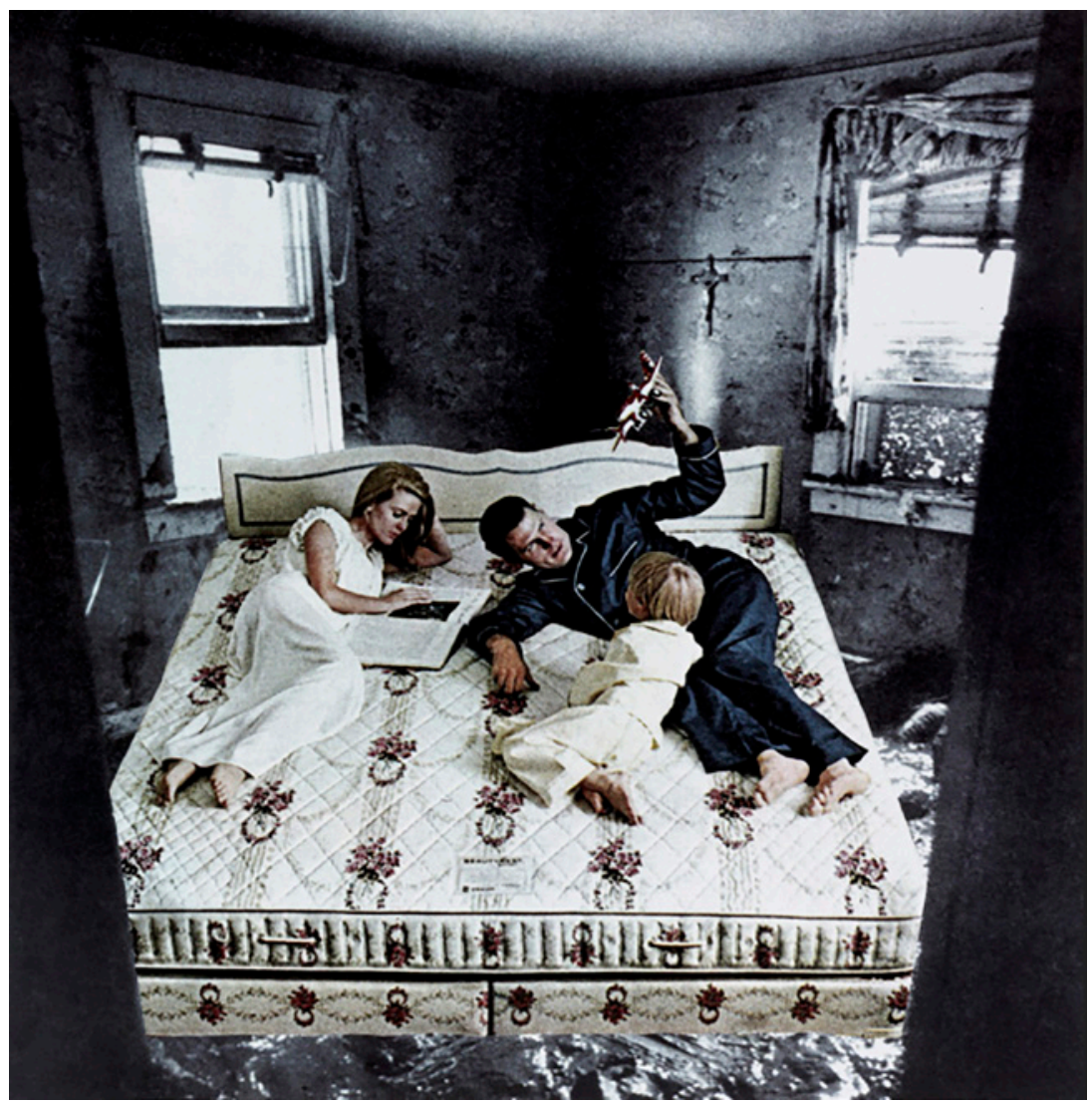

Imagen 3. Martha Rosler, Beauty Rest, 1967-1972. Fotomontaje, impresión de inyección de tinta pigmentada. MoMA The Museum of Modern Art. Fuente: https:/ /www.moma.org/collection/ works $/ 150120$

También desde la ironía, Birgit Jürgenssen (Viena, 1949-2003) en su díptico fotográfico Nonne (1979) expone el tropo de la mujer postrada y desvalida, con su propio cuerpo sobre el suelo cubierto por una sábana blanca, en una posición que juega a ser erótica. En la primera imagen podemos ver la cabeza de la artista, mientras que en la segunda, a través del fotomontaje, esta ha desaparecido de manera inquietante. Además, «unas máscaras (...) sobre sus pechos y vagina son testigos de lo que ocurre por encima de la sábana; bajo ésta, todo es enigma» (Pérez Gil, 2016: 365). Así, desde la erotización e insinuación de lo femenino, será una de las artistas que de manera más temprana subvierta esta imagen idílica. Idilio deconstruido también desde la visión de un cuerpo femenino enfermo, como es el caso de las fotografías de Hannah Wilke (Nueva York, 1940-1993), Handle with care (1987) e 
Intra-Venus (1992-1993) [Imagen 4]. En la primera aparece la propia autora, desnuda, en su cama, posando con sus periquitos al poco de serle detectado cáncer. En la siguiente, formando un tríptico, observamos su cuerpo ya con las cicatrices de las operaciones a las que se sometió. Si en Handle with care es patente una clara tensión en la expresión de la artista, en Intra-Venus expone sin tapujos las transformaciones de su cuerpo. Así, «la cama y la cámara» terminan siendo los «testigos presenciales del efecto de la enfermedad» (Pérez Gil, 2015: 409) donde la autora en lugar de aparecer derrotada, se muestra firme y valiente. Como vemos, el lenguaje directo de estas artistas rompe el halo de romanticismo asociado a la relación entre el lecho y la mujer.

Como se ha referido anteriormente acerca de la instalación artística en Krauss, esta modalidad artística subvierte la noción de espacio y de objeto artístico. Una obra coetánea a Rosler que tratará el tema de la invención de la domesticidad será Lea's Room (1972), de las estadounidenses Karen LeCocq (Santa Rosa, 1949) y Nancy Youdelman (Nueva York, 1948) para el proyecto Womanhouse, intervención de site-specific organizada por mujeres artistas que supuso «un intento de concretar las fantasías y opresiones de la experiencia de las mujeres» (Lippard, 1976: 64). «La sexualidad, el modernismo o la modernidad están organizados por la diferencia sexual, y son formas de organizarla. Percibir la especificidad de las mujeres es analizar históricamente una configuración particular de la diferencia», escribe a propósito Griselda Pollock (2013: 120). Así, las «instalaciones, performances, recitales de poesía y teatro» desarrolladas en este proyecto orbitaron «en torno a la necesidad de deconstruir el simbolismo y la carga social de cada rincón de la casa» (Aliaga, 2009: 39). Womanhouse se compuso de estancias muy irónicas, como un salón-comedor donde se criticará su condición de espacio para la concordia y la reunión al ser frecuentemente el lugar de la conversación formal, artificial, donde recibir a los invitados y guardar las apariencias (Rosa, 2011: 322), «un bañomenstruación», una «escalera nupcial», armarios de los que asomaban maniquís, «una habitación rosa con decoración de tetas-huevos frito», y un decimonónico «dormitorio en el cual la mujer se sienta y constantemente se maquillaba y cepillaba su cabello» (Lippard, 1976: 64). LeCocq y Youdelman lo exponen como un espacio de retiro privilegiado y «sofocante opresión» (LeCocq y Youdelman, 1972), un escenario donde todos los detalles estaban cuidados, desde «el fuerte y pugnaz olor de la magnolia» al «tono rosáceo de las rosas del papel de pared» (1972). La protagonista de la performance era «la cortesana Lea, una mujer que desesperadamente intentaba mantener su ya debilitada belleza» (1972), la cual trataba de compensar con un sombrero y un velo, para seguir sintiéndose deseada ante los hombres. La performance, «en la cual una mujer incesantemente se aplica capas y capas de maquillaje», retrataba «el dolor de la edad» (1972) y el vértigo ante el desvanecimiento de la belleza. 

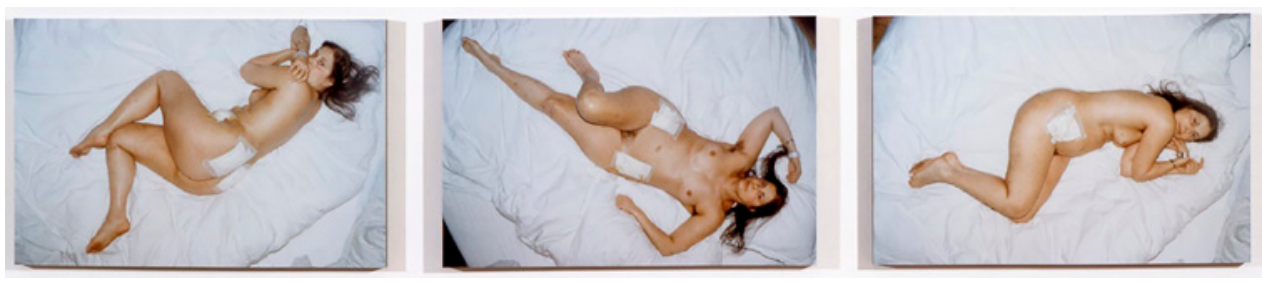

Imagen 4. Hannah Wilke, Intra-Venus (1992-1993). Fotografía a color. Ronald Feldman Gallery. Fuente: https: / feldmangallery.com/exhibition/164-intra-venus-wilke-1-8-2-19-1994

El miedo a la estima, la pérdida, así como la reclusión a la que la mujer ha sido sometida en la historia adquieren un gran reflejo en la histeria, una enfermedad considerada propia de la mujer y que el discurso médico defendía contribuyendo así al estigma y la misoginia (Perrot, 2009: 337, Didi-Huberman, 2007). En este sentido, el trabajo de Louise Bourgeois (París, 1911 - Nueva York, 2010) es remarcable, tratando habitualmente la cama y la habitación como escenario del dolor y el aislamiento, tanto desde sus inicios en el Surrealismo como en obras más cercanas a la estética posmoderna en despliegues cuasi escenográficos que llamó «celdas» (Crone y Schaesberg, 1998: 163). La histeria aparece en sus piezas recreando esta dolencia en una serie de tres esculturas que representan un cuerpo femenino decapitado. La postura arqueada recuerda a la que el cuerpo adquiría en las sesiones médicas del XIX (Pérez Gil, 2016: 405-6), y es evidente en Arched Figure no 1, 2 y 3 (1997), tres esculturas donde dicho cuerpo arqueado y sin cabeza parece estar poseído. Llevó a cabo numerosas versiones del proyecto, iniciado en 1989 y concluido en 2004, desde el dibujo y la escultura. La lectura de género es inevitable dado que la masculinidad hegemónica representa la prosperidad y lo enfermizo lo femenino (Butler, 2007: 259). Si a finales del XIX la moral victoriana que LeCocq y Youdelman criticaban imponía cómo debe comportarse una mujer, el tratamiento para las histéricas - para quienes no había habitaciones de hospital- requería además de un aislamiento en «nichos» e incluso «celdas» (337), de ahí el término que Bourgeois acuñó, donde «enfatiza el trauma físico y psicológico» (Mahon, 2017: 34).

El tema de la histeria ha tenido tanta presencia en el arte contemporáneo que excede nuestro estudio, no obstante no quisiéramos pasar sin citar otros tres ejemplos más, también muy relevantes, desde la fotografía, el vídeo y la instalación. La violencia de estas sesiones quedará relatada en la obra de Shana Lutker (Nueva York, 1978), H.Y.S.T. et al. (2010), un conjunto escultórico donde muestra fragmentados los instrumentos propios de las sesiones a las que se sometían las pacientes. La composición sugiere desolación, al encontrarnos con formas amenazantes y artefactos anacrónicos que Lutker «refina y estiliza devolviéndoles actualidad y dejando al descubierto las pulsiones agresivas que vehiculizan. Así, la histérica, que aparece representada solamente por sus piernas imperfectas, nos da a entender cómo alrededor de un objeto se produce toda una revolución instrumental» (Echeverría Alvarado, 2015: 724-5). Por otro lado, Victoria Manning, artista interesada en las relaciones entre historia, ciencia y arte, en su serie fotográfica Reposantes (2013) se 
coloca ella misma tras la cámara «actuando como histérica de La Salpêtrière» famoso hospital parisino fundado en el XVII que albergaba una cárcel de mujeres, a menudo vagabundas y prostitutas- y «reproduciendo las fases del ataque de «grande hystérie»» (Echeverría Alvarado, 2015: 703). De este modo, "propone su propia elaboración de las temáticas de la traducción, la re-actuación y las narrativas interrumpidas (...) de la histeria» (703). Además, el título Reposantes alude «a la fase de reposo que experimentaban las histéricas después de los ataques», de hecho en un texto médico del momento se decía que estas mujeres «quedaban incapacitadas para caminar, «como en reposo»» (703). Por último, desde la vídeo instalación, Marina Núñez (Palencia, 1966) en El Infierno son nosotros. Histeria y posesión (2012) interviene la Capilla del Museo de Arte Contemporáneo Español Patio Herreriano de Valladolid con ocho vídeo proyecciones animadas donde el tema del infierno en un espacio religioso es problematizado, apareciendo las siluetas de unas «mujeres endemoniadas que intentan escapar a su suplicio sin lograrlo» (Echeverría Alvarado, 2015: 623). La obra visibiliza a la histérica como «endemoniada», estigmatizada por la ciencia moderna, denunciando a su vez a aquellas que siglos antes «fueron quemadas vivas», equiparando «así el dolor y el sufrimiento que a unas y otras les infligiera la religión y la ciencia» (624).

\section{2.- La cama intervenida desde las artes menores y el ready made: sátira, ironía y poéticas intimistas y procesuales}

Otra de las principales estrategias para subvertir lo doméstico desde perspectivas feministas ha sido el empleo de las -así denominadas- artes menores como el bordado y el ready made, expandiendo a la vez la noción de objeto artístico. En la década de 1990 el movimiento conocido como YBA -Young British Artists- ejerció una gran influencia en cuanto al replanteamiento espacial y la crítica de la obra de arte, siempre desde la polémica y apoyado por un mercado del arte emergente. En este contexto, Sarah Lucas (Holloway, 1962) llevó, con Au naturel (1994) [Imagen 5], el colchón al espacio de exhibición en un gesto duchampiano que expone la parodia de la inmediatez misma del acto sexual y de la cama como soporte del placer y el sexo. Para ello la «interviene» con frutas y objetos que sugieren genitales (Lucas, 2005) y, como en «muchas de sus instalaciones, la construcción es informal, espontánea y realizada con materiales ya existentes» (Racz, 2015: 150). La obra parte de una investigación acerca de dos fotografías rescatadas por Linda Nochlin: la primera, titulada Achetez des pommes, de autoría desconocida en la que la mujer portaba unas manzanas (siglo XIX) mientras que en la segunda, con título Achetez des bananes, era el hombre el que sujetaba las bananas (parodia realizada por Nochlin), ambos desnudos en una sugerente asociación genital-fruta (151). Y es que la cama, «como nido y nudo que es, se ha manifestado siempre como un lugar de encuentros y de intercambios, de poder y de atracción, de ternura y de violencia» (Perrot, 2009: 446). Au naturel fue una de las piezas de Schlaflos / Sleepless: The Bed in History and Contemporary Art, la cual Mario Codognato también conecta con las metáforas populares acerca del sexo (Codognato, 2015: 21-22). 


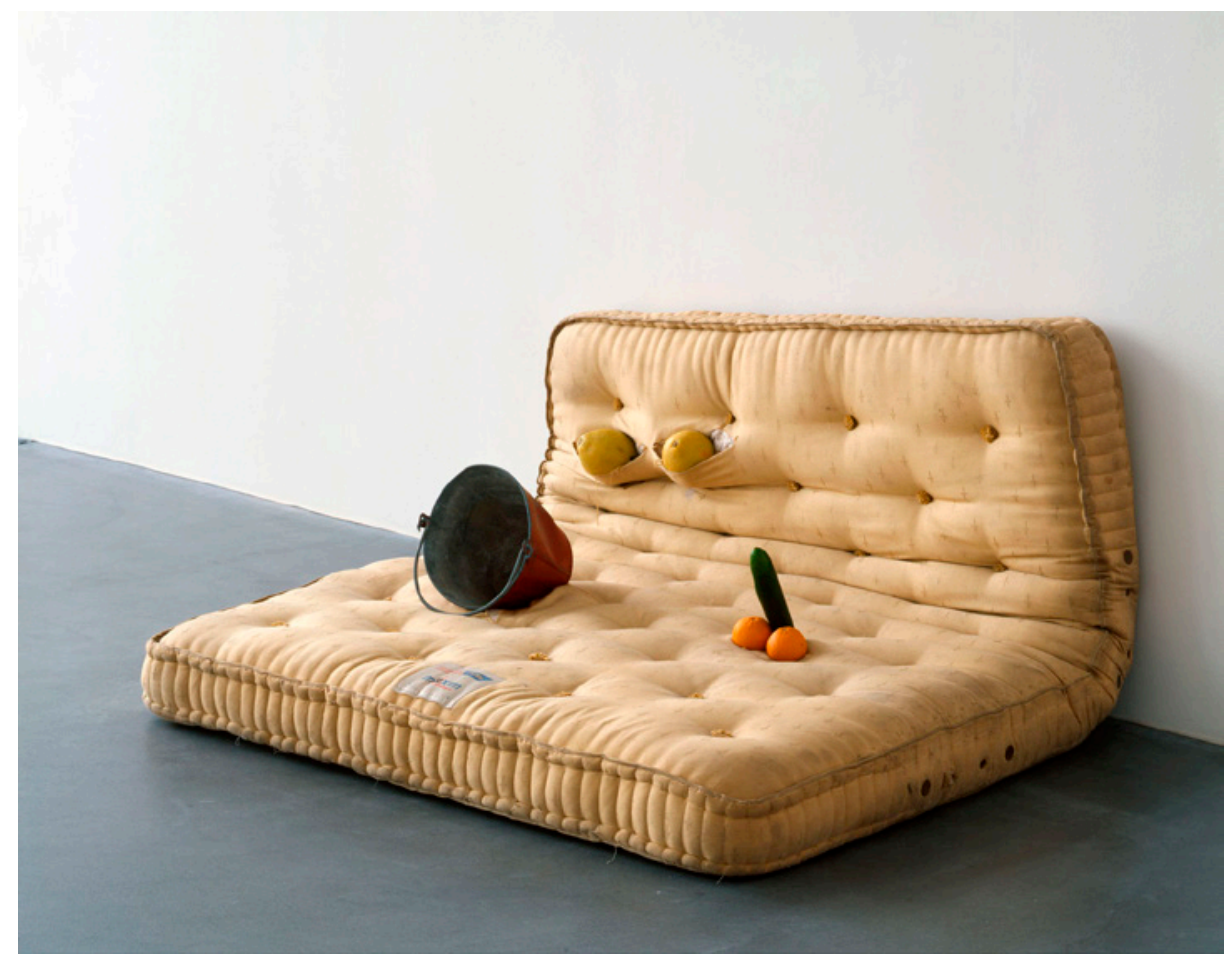

Imagen 5. Sarah Lucas, Au naturel, 1994. Ready-made, materiales diversos. Sadie Coles HQ. Fuente: https://hammer.ucla.edu/exhibitions/2019/sarah-lucas-au-naturel

En fuerte continuidad con el trabajo de descodificación sugerido acerca de la alusión a los órganos sexuales y la atención a la inmediatez, encontramos la obra sobre la cama más controvertida de los últimos tiempos, My Bed (1998), de Tracey Emin (Croydon, 1963). Hija de un turco-chipriota emigrado a Inglaterra, Emin creció en un hotel del cual su madre era la jefa. Estas vivencias infantiles serán una referencia repetida en sus trabajos, que juegan con el contenido de verdad de lo autobiográfico (Merck, 2002: 152-153). De hecho, como sentenciará en una entrevista: «El tema no soy yo, el tema comienza conmigo» (Taylor, 2011, 11' 05»). Siguiendo este postulado, Emin expone de manera cruda el que podría ser un encuentro afectivosexual violento donde ese descanso feliz es interferido por una lucha materializada en objetos que invitan a su recorrido: preservativos, botellas de alcohol, ropa interior, medicamentos (Racz, 2015: 148). Los objetos personales, llevados al espacio expositivo, se resignifican mezclando recuerdos con meras fantasías (Perry, 2013: 41). Si la cama, a menudo «lugar primero», testigo de la "violencia, del malentendido y la soledad» (Sperber, 2017: 24), más que un registro del encuentro, aquí es el encuentro mismo al llevar el lecho al propio ámbito expositivo. Escribe Mandy Merck en su artículo sobre la artista: «Las huellas (...) tan evidentes en sus sábanas dan testimonio de una tradición excremental» que comenzaría con Rauschenberg 
en torno a 1950 con pinturas en las que suelen aparecer periódicos pegados con pegamento o manchas de pintura (Merck, 2002: 125). Si en Bed (1955) Robert Rauschenberg hacía de su ropa de cama el lienzo, conectando el espacio del descanso y despreocupación con el espacio de atención de la galería, y donde la suciedad juega un papel importante (125), en «la ropa de cama de Emin, estas referencias (...) pueden interpretarse como un intento de conectar el cuerpo de la artista con la pieza» (125). El que además constante y compulsivamente registre su vida, puede entenderse como una exposición directa de su intimidad, pero continuamente liga realidad y artificio, con lo cual la teatralidad genera confusiones acerca del valor atribuido a la verdad y al objeto artístico en sí (Betterton, 2002: 33).

En muchos casos «la historia disfuncional de la familia de Emin» es «clave para entender la pieza» (Perry, 2013: 124), como también sucede en obras anteriores como Everyone I Have Ever Slept With 1963-1995 (1995) [Imagen 6], una instalación que transita el ready-made. Formada por una pequeña tienda de campaña, en ella explora la intimidad compartida del dormir junto a otra persona, invitando al/la espectador/a a curiosear su interior. Dentro de ella, en color rosa, están bordados «los nombres de todos los compañeros de Emin, en una letanía de amantes, amigos y familiares, incluyendo su hermano gemelo Paul, y dos fetos abortados» (33-34). Además, el bordado, con su "proceso lento y calculado", es «tradicionalmente una labor femenina» que ha sembrado el debate en torno a su posición respecto al arte feminista (33-34). La tienda de campaña tiene así este carácter aventurero (del alojarse en la naturaleza) pero también el aspecto sexual y efímero, pues «las formas de hacer el amor se han vuelto más indiferentes hacia la habitación o la cama», de ahí la recurrencia al «hotel, al backroom, al automóvil, a la tienda, a la playa o al bosque» (Perrot, 2009: 443). La urgencia -tanto de Emin a través de la cantidad de elementos dispuestos para un breve tiempo, como en Lucas con la irreverencia de una poco elaborada, cruda e incluso grosera construcción- aparece como un retrato de la dificultad de gestión y preocupación por esos momentos de goce tan característica de nuestro tiempo, y que según las historiadoras Sophie BodyGendrot y Kristina Orfali en Historia de la vida privada (1989) queda determinada, limitando sus posibles narrativas: «el empleo del tiempo es un fenómeno cultural» (Body-Gendrot y Orfali 1987, 170) que pauta nuestra economía libidinal (Lyotard, 1990): cómo nos relacionamos afectivamente en el espacio reservado al descanso, interferido por las horas posibles de reposo destinadas a él. 


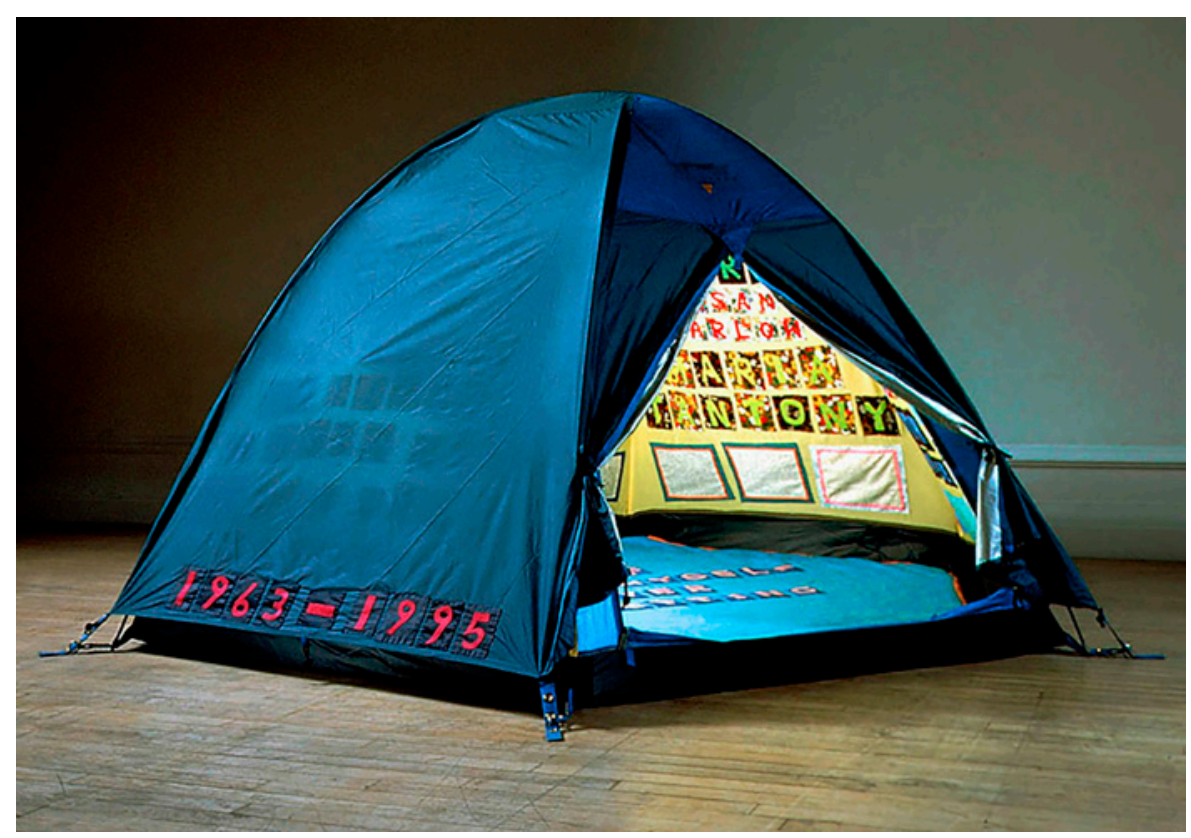

Imagen 6. Tracey Emin, Everyone I Have Ever Slept With 1963-1995, 1995. Instalación, materiales diversos. Saatchi Gallery (hasta su destrucción en un incendio en 2004). Fuente: https:/ /www. saatchigallery.com/aipe/tracey_emin.htm

Paralelo a este movimiento, y siguiendo la estela de Womanhouse y pioneras como Judy Chicago en los setenta y ochenta, destacamos las artistas feministas que hacia los noventa también cuestionan el objeto artístico pero desde una estética más intimista y procesual. En referencia al empleo de la costura que ya atisbamos en Emin, una de las autoras más conocidas es Jana Sterbak (Praga, 1955), quien en Attitudes (1987) presenta «cuatro camas, del mismo tamaño, forma y color, cubiertas con idénticos cubrecamas grises» (McLerran, 1998: 547). Sobre ellas, unas almohadas distribuidas cuyas fundas están bordadas con palabras en distintos colores «que describen «situaciones de cama»» (547), esgrimiendo conceptos de orden moral y sexual, como «Codicia», «Virtud», «Reputación», «Estética», «Ética» y «Enfermedad» (547). El resto de almohadas «están cubiertas con fundas de estilo característicamente americano y llevan la frase «fantasías sexuales»» (547). El hilo del bordado «proporciona color a la instalación» $\mathrm{y}$ «es iluminado para crear un alto contraste» entre «las almohadas (suaves, blandas y cómodas)» y «la cama (fría, angular y poco atractiva), que representa lo «masculino»» (550). En definitiva, la pieza explora «la semiología de la alcoba, examinando el papel del lenguaje en la construcción de la subjetividad sexuada» (547).

Una subjetividad que de continuo asocia los conceptos de lo saludable y lo enfermizo a los géneros. Si la casa nos otorga una sensación de protección (Bachelard, 2006: 130), la cama en tanto negativo del mundo externo (131) puede 
magnificar las preocupaciones al apagar la mirada. De hecho, el insomnio es una de las dolencias características de nuestra era «fluida», la cual está marcada por «la corrosión del carácter» que tanto las condiciones laborales como la falta de espacios para el encuentro con uno mismo y la proliferación de productos espectáculo suscitan (Sennett, 1998). Ya en su acción de 1994, Slumber (Dormitar), Janine Antoni (Bahamas, 1965) tejió sus sueños para visibilizar su insomnio. En primer lugar, la artista fue filmada durmiendo en el espacio del museo al tiempo que un sismógrafo iba registrando todo lo que soñaba (Cameron, 1995: 55). Después, tras despertar, Antoni fue bordando gracias a un telar las sugerentes formas que este aparato dibujó, culminando así en una suerte de manta-sudario siempre en proceso, ya que fue ampliándola con sueños posteriores (55). La obra, nuevamente, vuelve a reexperimentar la experiencia traumática a través del arte, conduciendo a una cierta terapia, ya que lo importante de esta pieza es su continuidad, su proceso, a la par que lleva al ámbito de las Artes un arte menor, tradicionalmente considerado como femenino. Tras Cocido y crudo (1995), muestra donde esta pieza se elaboró, La casa, il corpo, il cuore Konstruktion der Identitaten (Hegyi, 1999: 11-53) fue una influyente exposición que dio cabida a propuestas similares como la de Paloma Navares (Burgos, 1947). En su trabajo aparece nuevamente la subversión del reposo feliz presupuesto a la cama: un problema de visión le llevó a replantear su modo de trabajar, de ahí la insistencia en el cuerpo fragmentado, las jaulas, los botes de conserva y recipientes que aluden a la protección de una forma aséptica, recordando al entorno higiénico del hospital (Gras Balaguer, 1997: 14). Si en Antoni asistíamos al tema del insomnio, ahora presenciamos la figura del centinela, de quien vela el sueño del otro. Sus vídeo instalaciones sonoras Tránsito (2000), Travesías (2002) y Flores sobre el océano (2002) muestran personajes filmados en sus camas, a menudo en planos fijos donde aparecen aparentemente durmiendo o reflexionando en un estado de aislamiento inquietante que se refuerza con la presencia en el espacio de otros elementos, como sonidos o luces que nos hacen habitar la intimidad y recorrer el sueño de unos desconocidos (Navares y Muñoz, 2011: 260).

A este cierto voyeurismo contribuye la pieza During Sleep (2002), de Chiharu Shiota (Osaka, 1972), quien presenta en el espacio expositivo unas camas enlazadas por un entramado de hilo negro, motivo muy frecuente en su trabajo. Todo ello forma una suerte de tela de araña de la que es imposible escapar. El concepto de nido, pero también de prisión, está aquí presente. Es muy revelador que las camas escogidas para esta instalación sean de hospital, con su blanco aséptico, frente al hilo negro que las recorre. En cada una de estas camas, lo cual conecta con la propuesta de Navares, hay una mujer aparentemente dormida, haciendo por tanto de esta una pieza viva, que conecta también con la performance, una performance donde la quietud y la sensación de aprisionamiento es crucial (Pérez Gil, 2016: 383). Continuando esta línea, Anne Lindberg (Nueva York, 1962) presenta Sleep (2005) [Imagen 7], donde trabaja la almohada en tanto lienzo, en tanto espacio a intervenir como Roszika Parker mantenía sobre el arte de la costura (Parker, 2017). Sobre la funda de esta ha bordado a mano unos versos del texto The Walking de Theodore Roethke (1953): «Me despierto para dormir, y tomo mi despertar despacio» (Solo- 
mon Godeau, 2015). Arguye la comisaria Abigail Solomon-Godeau -pues la obra fue expuesta en el ciclo de exposiciones The Century of the Bed (2014) donde esta participó- que la almohada aparece aquí como un límite que habitar entre lo consciente y lo inconsciente (Solomon Godeau, 2015), reivindicando ese tránsito que invita en su horizontalidad. La almohada, que también vimos en Sterbak, conecta la finitud consciente con la infinitud de los sueños (Pérez, 2010: 21-22) en tanto umbral a lo inefable. Finalmente, otro punto que enlaza las propuestas de estas autoras es cómo continúan la noción de campo expandido así como la «desmaterialización del objeto», término acuñado por Lucy R. Lippard (1976), rasgo basal en toda apuesta feminista al eludir la catalogación disciplinar para afirmarse como prácticas que supeditan el medio a la idea (Ardenne, 2000: 10).
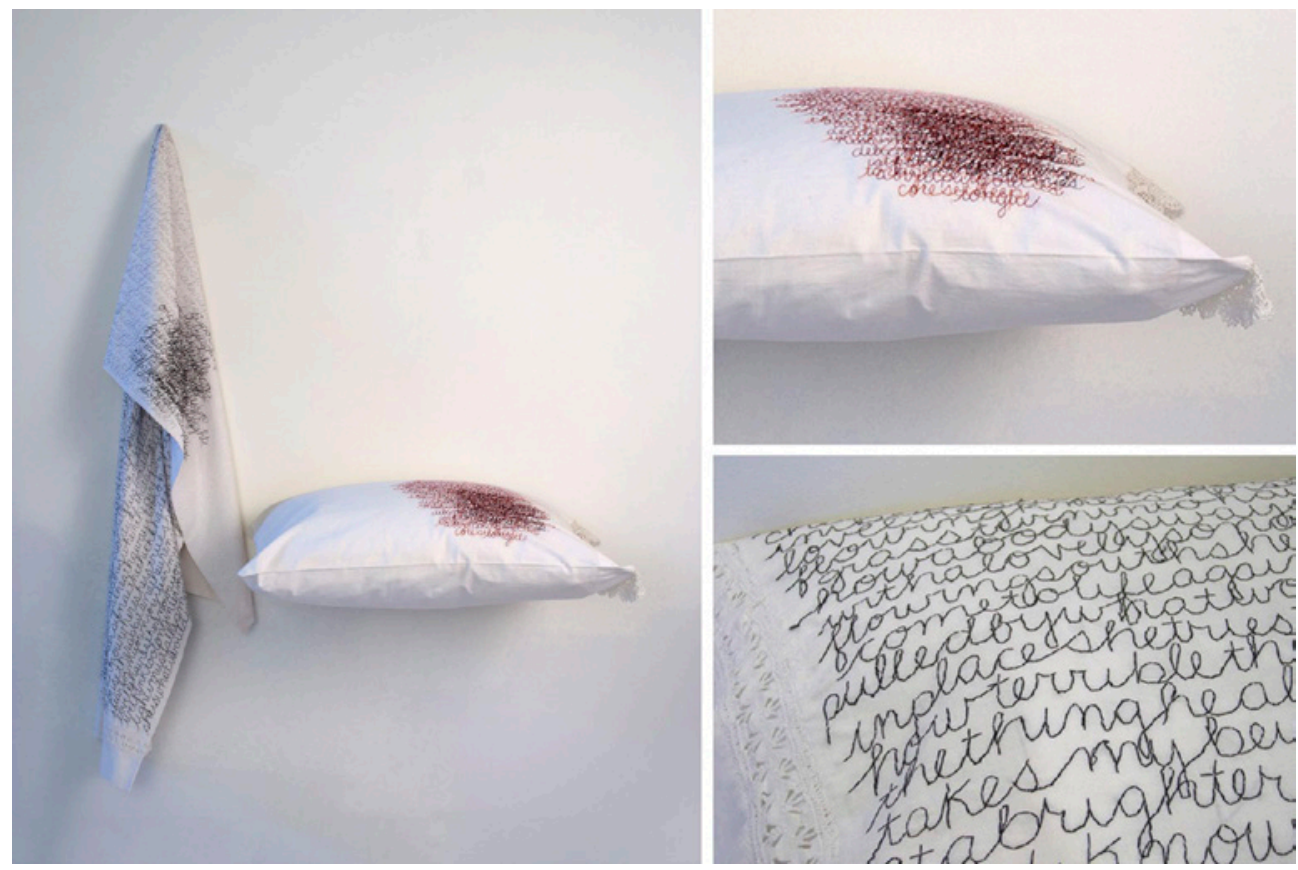

Imagen 7. Anne Lindberg, Sleep, 2005. Escultura, hilo de rayón y fundas de almohada. Colección privada. Fuente:

http:/ / www.annelindberg.com/working-news-page/2014/8/20/sleepless-nights-curated-by-abigailsolomon-godeau-galerie-hubert-winter-vienna-austria-opens-3-october-2014

\section{3.- La cama a la intemperie para un arte expandido al albor del cambio de milenio: precariedad, violencia, vigilancia}

$\mathrm{Si}$, como hemos comentado, todo reposo requiere de una cierta custodia, también implica un coste, un mantenimiento. La cotidiana presencia de colchones en el paisaje urbano revela cómo la cuestión del acceso a la vivienda es crucial en nuestros días, cómo el descanso está también mediado por la economía. En este 
sentido, coincidiendo con la popularización del término homeless tras las polémicas políticas de Reagan y Tatcher en los noventa, y de un arte activista que crecientemente denuncia cuestiones relacionadas con la precariedad y la exclusión social (Martínez-Collado, 2017: 40-41), Rachel Whiteread (Londres, 1963) en sus esculturas trata con frecuencia el tema de la gentrificación y la carencia de hogar. Destacamos así su serie de vaciados de colchones encontrados en la calle. En Untitled (Amber Double Bed), 1991, lleva los detalles de un colchón abandonado a su obra, fosilizando la precariedad y la suciedad del mismo en la escultura resultante y trasladándola al cubo blanco de la galería. También incide en hasta qué punto una cama es una cama en función de dónde se encuentre, así como la dislocación y el trauma que suscita la posibilidad de verse forzado/a a dormir a la intemperie (Codognato 2007, 17-20). Estas piezas están fabricadas en fibra de vidrio, goma o yeso, e inspiran un recorrido por las posibles historias que estos colchones han presenciado a través de sus detalles, marcas y hendiduras (17-20).

Una artista presente en la mayoría de exposiciones anteriormente señaladas y probablemente la más célebre en referencia al empleo de objetos domésticos en sus obras es Mona Hatoum (Beirut, 1952). Instalada en Londres forzosamente al no poder regresar a Líbano tras estallar la guerra mientras se encontraba de viaje en Inglaterra, la exploración de la casa y la nostalgia de un lugar que habitar se convertirán en el tema central de su trabajo. Daybed (2008) [Imagen 8] es una escultura en hierro que imita la forma de un rallador de queso. Pero este rallador mide dos metros de largo y es instalado en el espacio horizontalmente, sugiriendo ser una suerte de cama (no provisional sino diaria, como reza el título), y tanto la dureza de su material como la absurdez de su supuesto uso contribuyen a este extrañamiento. A menudo, sus muebles-utensilios de cocina, construidos en hierro, transportan un carácter frío y peligroso en lugar de acogedor. Aquí estamos ante una cama inhóspita, incómoda, que amenaza más que protege, cuyas formas «duras, metálicas, industriales», recuerdan a los preceptos del Minimalismo (Garb, 2002: 24). Aparece aquí, además, el sueño como algo exhibido, deviniendo un escenario de acuerdo colectivo, quebrando toda privacidad en una rigidez y uniformidad que no invita al descanso (24). La figura humana, ausente en todas sus esculturas, sugiere la obliteración individual y pérdida de todo arraigo (24) para denunciar las condiciones de vida cotidiana de millones de personas migrantes abocadas a habitar la intemperie y luchar constantemente con una identidad reprimida. 


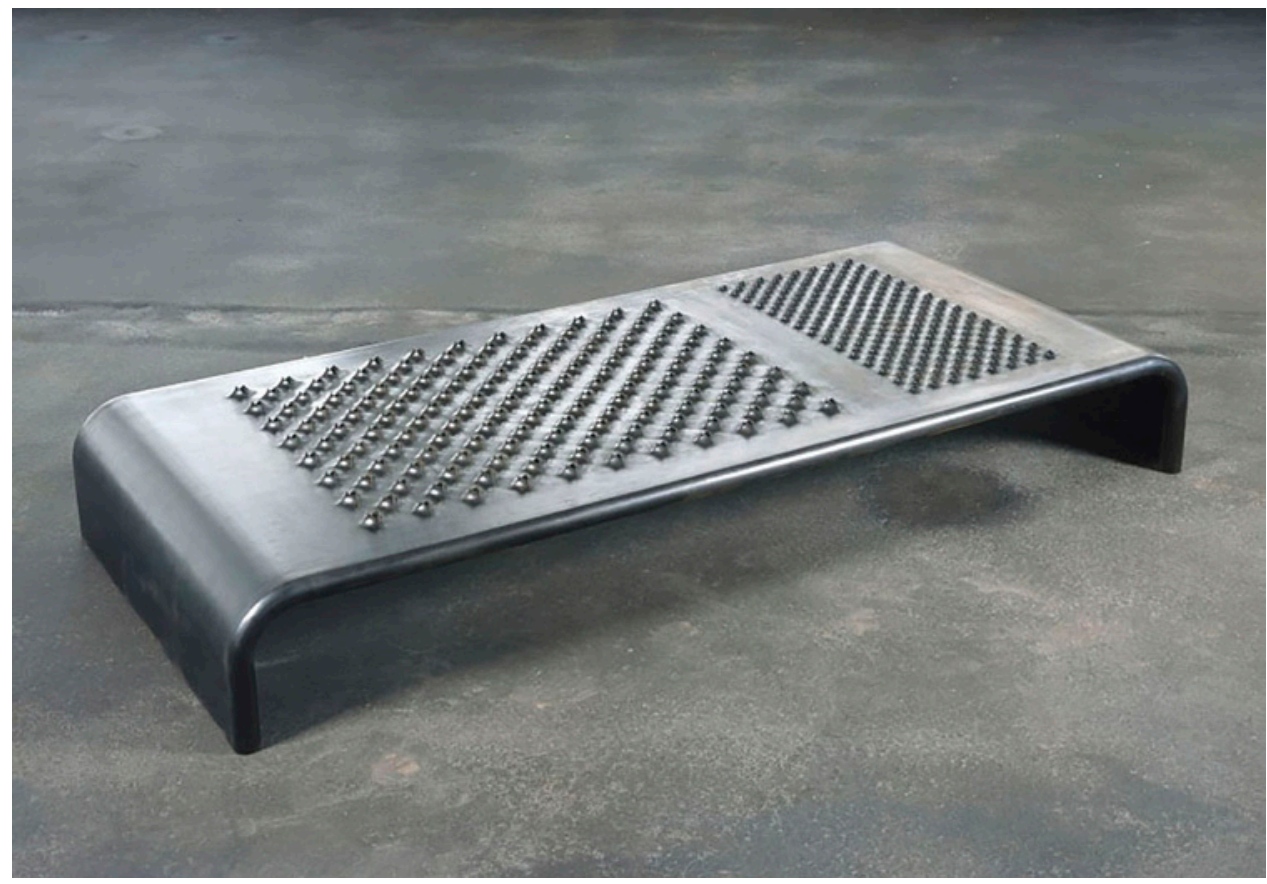

Imagen 8. Mona Hatoum, Daybed, 2008. Escultura en hierro. Galerie Max Hetzler. Fuente: https:/ / www.artbasel.com/catalog/artwork/43916/Mona-Hatoum-Daybed

La cama, como vemos, pasa a ser un objeto público, al que también artistas como Marina Núñez, Sophie Calle y Julia Scher contribuirán en esta época. Marina Núñez, que ya apreció anteriormente, en su dibujo sobre servilleta Sin título. Serie siniestro (1994), representa la vigilancia de un dormitorio burgués a través de los ojos que sobresalen del cuadro de la pared. Así, «ese lugar de confort burgués decimonónico ideal, señalado con los significantes del Romanticismo y la almohada en forma de corazón, es desvelado como el lugar de lo siniestro con que la autora titula la obra» (Echeverría Alvarado, 2015: 774). El empleo de la servilleta, en este caso de lino, aporta un carácter precario y efímero. Desde el vídeo (un vídeo también precario), Sophie Calle (París, 1953) explora este cierto voyeurismo y exposición obscena de la intimidad en No sex last night (Double Blind), de 1992, donde diluye la relación entre creador/a y objeto de representación, así como juega con los límites entre lo real y lo ficticio. En un viaje a San Francisco por motivos laborales junto a su pareja, ya en un momento muy deteriorado de la relación, documentó diariamente todo cuanto ocurría en el trayecto con una videocámara doméstica. Las escenas están filmadas tanto por él como por ella, cada uno aportando una sugerente voz en off y su propia interpretación de lo que sucedía, derivando el montaje final en una película fragmentaria, llena de tensión, tanto en los momentos en el coche como en los hoteles donde pernoctaban. En este sentido, los planos de las camas, a menudo deshechas, actuaban a modo de leitmotiv y diario (Calle, 2003: 325-334). 
También haciendo uso del dispositivo vídeo, Julia Scher (Hollywood, 1954) en Surveillance bed III (2000) [Imagen 9] instala alrededor de una cama un conjunto de cámaras que la filman constantemente desde cada una de sus esquinas. Se invitaba a los/as espectadores/as a tumbarse en la cama, interactuar con ella, de ahí que sus sábanas aparecieran revueltas. Los «sistemas de vigilancia» que la artista instala en sus piezas desde los años noventa, escribe Dan Cameron, tienen como objetivo desconcertar al/la espectador/a para hacerle tomar conciencia de los límites de la obra, propiciando una reflexión acerca de una sociedad altamente informatizada que precisa de la intimidad de los individuos para ejercer su control (Cameron, 1995: 53).

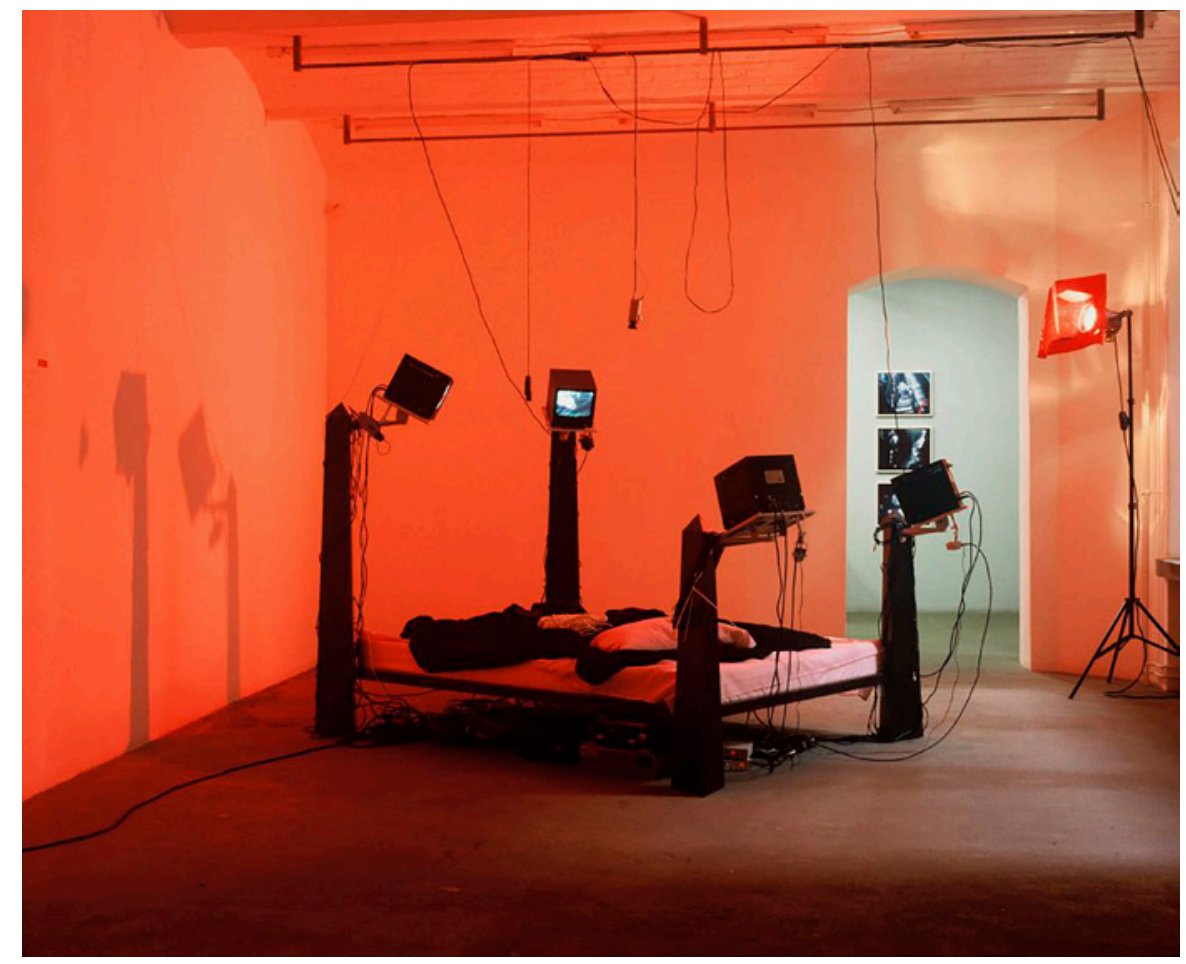

Imagen 9. Julia Scher, Surveillance bed III, 2000. Instalación, materiales diversos. Galería Schipper \& Krome. Fuente: https:/ / kunstkritikk.com/dirty-data/

Como vemos, uno de los giros más importantes en el arte contemporáneo actual tiene que ver con el cuestionamiento de los límites de lo privado. En este sentido, la visibilización y denuncia de la violencia de género, ya desde autoras como Ana Mendieta o Suzanne Lacy ha sido frecuente. A continuación, señalaremos a las dos últimas artistas de nuestro recorrido, Jana Leo y Emma Sulkowicz, las cuales trabajan este tema. La instalación Rape Room (2002), de Jana Leo (Madrid, 1965) se basa en su propia experiencia, pues fue violada por un asaltante en su propia casa, y consta de una habitación creada específicamente para la obra -cuyo título fuera de 
la misma es expuesto en vinilo de color rosa y una tipografía cursiva, dándole un tono romántico-, a la cual se accede desde la puerta de una esquina de la misma. El habitáculo queda presidido por su propia cama -volvemos a ver el recurso a la cama real en el espacio expositivo como en Scher- y en el papel de pared que decora el cuarto encontramos un motivo que se repite: la fotografía de una de las heridas que sufrió durante la violación en su cama. La escalofriante escena queda completada con dos lámparas a cada lado del lecho, sobre sendas mesillas de noche. Su historia sería publicada en Rape New York (Leo, 2011) y, como mantiene la artista, «Rape Room reconstruye el proceso recíproco de afección entre un espacio y una persona» (Leo, 2019). El uso del papel de pared tiene varias connotaciones, ya que este queda superpuesto en diversas capas sobre la misma «como los trazos de un recuerdo. Algunas capas cubren a otras, pero la transparencia es selectiva» (Leo, 2019). El papel en tanto soporte "en el cual escribimos nuestra historia», y a la par «la capa más externa de la pared» (2019) repite un mismo patrón: la fotografía «de una herida con forma vaginal» el cual al ser multiplicado en el espacio evoca una pesadilla, un trauma persistente tras la violación (2019). En su libro El viaje sin distancia (2004), partiendo de distintas investigaciones, Leo mantiene que es en los domicilios donde se producen gran parte de las violaciones (un 32\%), a menudo perpetradas por «familiares cercanos» $\mathrm{y}$ «otros hombres que eventualmente visitan la casa o tienen acceso a ella» (2004: 279). Del mismo modo, recoge cómo según «las estadísticas de varias asociaciones en contra de la violación en Nueva York, en 1992 (...) una de cada ocho mujeres adultas era violada a lo largo de su vida, y de ellas dos lo eran en su domicilio», lo cual se intensifica en las zonas residenciales al tener estas «un mayor grado de aislamiento» (280).

Continuando con esta línea, en la acción Mattress Performace (Carry That Weight), (2014-2015), [Imagen 10] la artista Emma Sulkowicz (Nueva York, 1992) también denuncia de manera explícita la problemática. Se trataba de una performance que alcanzó gran difusión mediática, donde las fronteras entre la obra de arte y el alegato o la reivindicación política, una estrategia eminentemente feminista, resultan difusas. Para su trabajo de Tesis -escribe Johanna Fateman- en la Universidad de Columbia, decidió realizar la acción de cargar con su colchón, «un colchón de dormitorio estándar, de cincuenta libras» (Fateman, 2018: 178), por todo el campus. Allá donde fuera, este sería su acompañante. La obra duraría, según anunció, «mientras que su acusado violador, un compañero de estudios, permaneciera matriculado en Columbia» (178), su universidad, y, por lo tanto, frecuentando las mismas inmediaciones de la artista. De este modo, entorno laboral y doméstico quedan interpelados. Al cargar cotidianamente con este «accesorio banal y engorroso», insiste y alerta acerca de la violencia y «la tiranía sexual», en este caso materializada en algo tan común y apreciado como es la propia cama, así como lleva a cabo una crítica a la incapacidad del sistema para resolver la situación. De este modo, «la marca de la violación del cuerpo» sale a la luz, haciendo de ello "una responsabilidad pública» (178). 


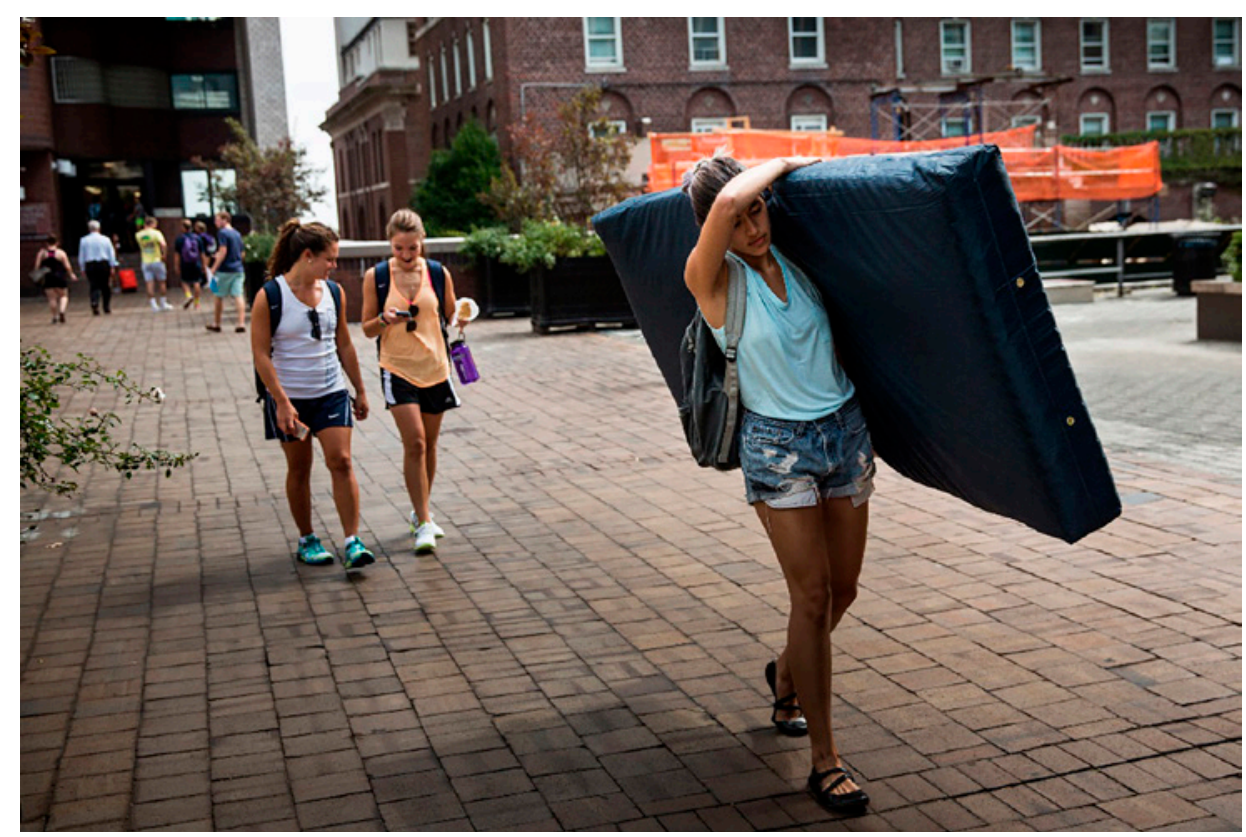

Imagen 10. Emma Sulkowicz, Mattress Performace (Carry That Weight), 2014-2015. Performance. Colección privada (documentación fotográfica). Fuente: https://news.artnet.com/exhibitions/dremma-sulkowicz-project-795176

\section{4.- Conclusiones}

Durante nuestro recorrido sobre el tropo de la cama en las artistas contemporáneas desde una óptica feminista, y tras la genealogía dibujada en el punto «2. Mujer y lecho en la Historia de la Pintura (siglos XVI-XIX)», podemos inferir dos ideas principales:

1) La relación tan arraigada entre el cuerpo de la mujer y el ámbito doméstico del dormitorio abarca una parte destacada de la Historia del Arte en Occidente desde principalmente el siglo XVI al XIX. La mujer aparece cosificada, fetichizada desde la mirada heteropatriarcal y misógina de la época, pero en los pocos ejemplos de mujeres artistas (rescatados por historiadoras como Griselda Pollock) encontramos unas escenas opuestas a las de sus homólogos masculinos, sin romanticismos. Aunque no han tenido lugar las principales revoluciones feministas, ya hay una crítica latente en sus aportaciones.

2) La presencia de la cama desde la segunda mitad del XX y comienzos del XXI toma un posicionamiento marcadamente político al acceder la mujer de manera progresiva al mercado laboral y al ámbito artístico. Además, la pintura resulta insuficiente para cuestionar la Historia del Arte oficial, y por ello las artistas expanden la noción de objeto artístico a otros medios y disciplinas. Así lo apreciamos a través de la selección de artistas proporcionada a partir de las exposiciones de referencia sobre el tema y la literatura relacionada a dichas prácticas artísticas. Este análisis ha resultado en tres puntos clave. 
Del primer punto, «La feminización de la cama como escenario de subordinación y enfermedad: respuestas desde la fotografía, el vídeo y la instalación», concluimos la importancia del uso pionero de medios no convencionales para impulsar una crítica al sistema artístico así como al opresor concepto de «ángel del hogar»y el tema de la histeria desde fines de los sesenta. Del segundo punto, «La cama intervenida desde las artes menores y el ready made: sátira, ironía y poéticas intimistas y procesuales», recogemos las dos principales tendencias que, desde mediados de los ochenta y los noventa (una más revulsiva, otra más poética), han caracterizado a las obras feministas sobre la cama. Y del tercero, «La cama a la intemperie para un arte expandido al albor del cambio de milenio: precariedad, violencia, vigilancia», más enfocado en el arte desde el 2000 a la actualidad, destacamos cómo la desarticulación de los sistemas sexo/género en el ámbito privado se expande a la denuncia social de la violencia de género, los mecanismos de control y los efectos de la globalización en busca de una toma de conciencia colectiva acerca de la temática.

Así, desde el cuestionamiento de la realidad más inmediata y aparentemente inocua de la vida cotidiana, de la casa y el dormitorio, es posible la creación de contra-imaginarios que contribuyan a una crítica social, donde el arte desarticule y visibilice las lógicas estetizadoras que tanta violencia y opresión ejercen y que, por cotidianas, pasan desapercibidas.

\section{NOTA ACLARATORIA}

Todas las traducciones presentes en este artículo forman parte del autor.

\section{Referencias}

AliagA, Juan Vicente (2009). «Lo público y lo privado: entrecruzamientos productivos». En Martha Rosler. La casa, la calle, la cocina (cat. exp., comisario Juan Vicente Aliaga). Granada: Centro de Arte José Guerrero, pp. 20-47.

AlPers, Svetlana (1987). El arte de describir. El arte holandés en el siglo XVII, Madrid: Hermann Blume.

Archer, Michael (1994). «Towards Installation», en De OliveIRA, Nicolas, OxLEY, Nicola y Petry, Michael (eds.). Installation Art. Londres: Thames \& Hudson, pp. 11-31.

Ardenne, Paul (2000). «L'art 'micropolitique', genealogie d'un genre», en Micropolitiques (cat. exp. comisarios Paul Ardenne y Catherine Macel). Grenoble: Centre National d'Art Contemporain de Grenoble, pp. 9-14.

BACHELARD, Gaston (2006). La tierra y las ensoñaciones del reposo, México D. F.: Fondo de Cultura Económica.

BetTERTON, Rosemary (2002). «Why is my art not as good as me? Feminite, feminism and 'Life-Drawing' in Tracey Emin's art». En The art of Tracey Emin (Chris Townsend, Mandy Merck y Peter Osborne eds.). Londres: Thames \& Hudson, pp. 22-39.

Body-Gendrot, Sophie y Orfali, Kristina (1987). «¿Modelos extranjeros?». En Historia de la vida privada. El siglo XX: diversidades culturales. (Georges Duby y Phi- 
lippe Aiès eds.). Madrid: Taurus, pp. 143-232.

Borzello, Frances (2006). En casa. El interior doméstico en el arte, Barcelona: Electa.

Bourdieu, Pierre (2000). La dominación masculina. Barcelona: Anagrama.

Brown, Christopher (1984). «The World of Work». En Scenes of Everyday Life: Dutch Genre Painting of the Seventeenth Century, Londres: Faber \& Faber, pp. 88-131.

ButLER, Judith (2007). El género en disputa. El feminismo y la subversión de la identidad, Barcelona: Paidós Ibérica.

Calle, Sophie (2003). M'as tu vue. París: Centre Pompidou, Éditions Xavier Barral.

CAmeron, Dan (1995). «Cocido y crudo», en Cocido y crudo (cat. exp., comisario Dan Cameron), Madrid: MNCARS, pp. 44-59.

Clayson, Hollis (1991). Painted love: Prostitution in French Art of the Impressionist Era. New Haven y Londres: Yale University Press.

CieraAd, Irene (2006). «Dutch Windows. Female Virtue and Female Vice». En At home: an anthropology of domestic space (Irene Cieraad ed.). Syracusse: Syracuse University Press, pp. 31-52.

Codognato, Mario (2007). «Found existence». En Whiteread (cat. exp., comisario Mario Codognato). Nápoles y Milán: Donnaregina Museum of Contemporary Art y Mondadori Electa.

Codognato, Mario (2015). Schlaflos / Sleepless. The bed in history and contemporary art. (cat. exp., comisario Mario Codognato), Viena: Belvedere.

Colomina, Beatriz (2014). «The Century of the Bed», en Colomina, Beatriz, RumpFHUBER, Andreas y RuHs, August (eds.). The Century of the Bed, Viena: Museum Moderner Kunst, pp. 19-23.

Crone, Rainer y Schaesberg, Petrus (1998). Louise Bourgeois: the secret of the cells, Michigan: Prestel Art Book.

DERRIDA, Jaques (2019). El factor de la verdad. Sevilla: Mármol Izquierdo editores.

Didi-Huberman, Georges (2007). La invención de la histeria. Charcot y la iconografía fotográfica de la Salpêtrière. Madrid: Cátedra.

ECHEVERRÍa Alvarado, Priscila (2015). La representación de la mujer en la iconografía de la histeria realizada por Jean Martin Charcot en la clínica de la Salpêtrière: La mirada exaltada del surrealismo y la apropiación alegórica del arte contemporáneo. Madrid: Universidad Autónoma de Madrid. [Tesis Doctoral]. Disponible en: https:// repositorio.uam.es/handle/10486/668002 (Fecha de consulta: 27/02/2021).

FATEMAN, Johana (2018). «Fully Loaded. Johanna Fateman on power and sexual violence». Artforum, No 56 (5), pp. 177-183.

GARB, Tamar (2002). «Nostalgia de hogar». En Mona Hatoum (cat. exp., comisaria Cristina Zelich). Santiago de Compostela: Centro de Arte de Salamanca, Centro Galego de Arte Contemporanea, pp. 17-31.

GIDDENs, Anthony (1992). La transformación de la intimidad. Sexualidad, amor y erotismo en las relaciones modernas. Madrid: Cátedra.

Gras balaguer, Menene (1997). «En el abismo interior», en Paloma Navares. Luces de hibernación (cat. exp., comisaria Menene Gras Balaguer). Valladolid: Junta de Castilla y León, pp. 15-25.

Gras BALAGUER, Menene (2001). «Escenarios domésticos o instrucciones para cons- 
truir la soledad». En Escenarios domésticos / Etxe arteak (cat. exp., comisaria Menene Gras Balaguer). San Sebastián: Koldo Mitxelena Kulturunea, pp. 6-22.

HeIdegger, Martin (2015). Construir Habitar Pensar / Bauen Wohnen Denken, Madrid: La Oficina.

Heller, Agnes (1985). Historia y vida cotidiana. Aportación a la sociología socialista, México d. f.: Grijalbo.

Hegyi, Lórand (1999). «La casa, il corpo, il cuore». En La casa, il corpo, il cuore: Konstruktion der Identitaten (cat. exp., comisario Lóránd Hegyi). Viena: Museum Moderner Kunst Stiftung Luwdig, pp. 11-53.

Hughes, Robert (2003). Lucian Freud. Paintings. Londres: Thames \& Hudson.

JohunG, Jennifer (2012). Replacing home. From primordial hut to digital network in contemporary art, Minneapolis y Londres: University Minnesota Press.

Krauss, Rosalind (2002). «La escultura en el campo expandido». En Foster, Hal (ed.): La Posmodernidad. Barcelona: Kairós, 2002, pp. 59-74.

LeCoce, Karen y Youdelman, Nancy (1972). Womanhouse. Los Ángeles: CalArts. Disponible en: http://www.womanhouse.net/works/3mdvx9wcrhllxdiw737d z9es89dk4q (Fecha de consulta: 27/02/2021).

Leo, Jana (2004). El viaje sin distancia. Perversiones del tiempo, el espacio y el dinero ante el límite en la cultura contemporánea. Murcia: CENDEAC.

Leo, Jana (2011). Rape New York. Nueva York: The Feminist Press.

Leo, Jana (2019). Domestophobia. Disponible en: https://janaleo.com/2016/03/18/ domestophobia/ (Fecha de consulta: 27/02/2021).

LipPARD, Lucy R. (1976). «Household images in art». En The Pink Glass Swan. Selected Feminist Essays on Art (Lucy R. Lippard ed.) Nueva York: The New Press, pp. 62-66.

LucAs, Sarah (2005). Sarah Lucas. Exhibitions and Cathalogue Raisonné 1989-2005. Ostfildern-Ruit: Hatje Cantz Verlag.

LyotARD, Jean-François (1990). Economía libidinal. Buenos Aires: Fondo de Cultura Económica.

Mahon, Alyce (2017). «Gender Politics at the Home: A Place of Intimacy». En No Place Like Home (cat. exp., comisaria Amina Kamien-Kazhdan). Jersualén: The Israel Museum, pp. 24-36.

MARTíneZ-Collado, Ana (2017). «Imágenes/secuencias, políticas de la identidad y la vida a través del videoarte en nuestra historia reciente». En MARTínezCollado, Ana y José Luis Panea, Secuencias de la experiencia, estadios de lo visible. Aproximaciones al videoarte español, Madrid: Brumaria y Ediciones de la Universidad de Castilla-La Mancha, pp. 21-50.

MercK, Mandy (2002). «Bedtime». En The art of Tracey Emin (Chris Townsend, Mandy Merck y Peter Osborne eds.). Londres: Thames \& Hudson, pp. 119-133.

MCLERRAN, Jennifer (1998). «Disciplined Subjects and Docile Bodies in the Work of Contemporary Artist Jana Sterbak», Feminist Studies, Vol. 24, Nº 3 (Otoño), pp. 535-552.

Navares, Paloma, y Muñoz, Tino (eds.) (2011). Paloma Navares. Travesía. Paisajes de interior (cat. exp). Madrid: Centro de Arte Complutense. 
NiETzsche, Friedrich (1976). Así hablaba Zaratustra. Un libro para todos y para nadie. México D. F.: Editores Mexicanos Unidos.

ОвRIST, Hans Ulrich (2019). Breve historia del comisariado. Madrid: Exit.

Olivares, Rosa (1992). «El río de la vida», Lápiz. Revista Internacional de Arte, No 87, pp. 36-43.

ØRSKou, Gitte (2003). «The Psychology of the Home», en Home sweet home (cat. exp., comisaria Gitte Ørskou), Aarhus: Aarhus Kunstmuseum, pp. 16-54.

PallasmaA, Juhani (2016). Habitar, Barcelona: Gustavo Gili.

PANEA, José Luis (2017). «Desvíos (de) hogar: hacia una relectura de la teoría de las dos esferas desde una perspectiva de género en la obra de Christiane Rochefort. Reposo y resistencia(s)», en VIII Congreso de la SAF: El tema de nuestro tiempo: Historia, Tópos, Éxodos. In Memoriam Eugenio Trías. Barcelona: UNED y Universitat de Barcelona, 28 de abril.

PARKER, Rozsika (2017), The Subversive Stitch: Embroidery and the Making of the Feminine, I.B. Tauris, Londres.

Perec, Georges (2007). Especies de espacios. Madrid: Montesinos.

PÉrez, David (2010). «Elogio y nula refutación del lecho frente al hecho de lo humano». En A piel de cama: miradas sobre un espacio cotidiano (cat. exp., comisaria Maite Ibáñez). Valencia: Sala Parpalló, pp. 15-25.

Pérez GIL, María (2016). Tras la carne otra carne se pudre: mujer, enfermedad, feminidad y arte contemporáneo. Madrid: Universidad Complutense de Madrid [Tesis Doctoral]. Disponible en: https://eprints.ucm.es/39151/ (Fecha de consulta: 27/02/2021).

Perrot, Michelle (2009). Historia de las alcobas, Madrid: Siruela.

Perry, Gill (2013). Playing at Home: The House in Contemporary Art. Londres: Reaktion Books.

Pollock, G. (2013). Visión y diferencia. Feminismo, feminidad e historias del arte. Buenos Aires: Fiordo.

Preciado, Beatriz (2010). Pornotopía. Arquitectura y sexualidad en Playboy durante la Guerra Fría. Barcelona: Anagrama.

Racz, Imogen (2015). Art and the Home. Comfort, Alienation and the Everyday. Londres: I. B. Tauris.

RichaRD, Nelly (1986). «The Rhetoric of the body», Art \& Text, No 21, pp. 141-144.

Rosa, María Laura (2011). Fuera de discurso. El arte feminista de la segunda ola en Buenos Aires [Tesis Doctoral]. Madrid: UNED.

RybczYNSKI, Wytold (1989). La casa: historia de una idea. Madrid: Nerea.

SANJUÁn, Ruth (2020). Archivos familiares, propios y apropiados como cuerpos narrativos para una memoria genealógica, Arte y políticas de identidad, $\mathrm{N}^{\circ} 22$, $\mathrm{pp}$. 56-72.

SARTRE, Jean Paul (2006). «El existencialismo es un humanismo». En GómEz, Carlos (ed.). Doce textos fundamentales de la ética del siglo XX. Madrid: Alianza, pp. 134162.

SENNETT, Richard (1998). La corrosión del carácter. Las consecuencias personales del trabajo en el nuevo capitalismo. Barcelona: Anagrama. 
Serota, Nicolas, y Ross, David A. (2000). Quotidiana. The Continuity of the Everyday in 20th Century Art (cat. exp., comisarios David A. Ross, Nicholas Serota, Ida Gianelli, Giorgio Verzotti y Jonathan Watkins). Milán: Charta.

Sibilia, Paula (2014). «La era de la extimidad: el universo doméstico se sube al escenario», en Asuntos domésticos (cat. exp., comisarios Pedro Vicente y Alexandra Laudo). Huesca: VISIONA y Diputación Provincial de Huesca, pp. 35-48.

Solomon-GodeAU, Abigail (2014). Sleepless Nights (cat. exp., comisaria Abigail Solomon-Godeau). Viena: Galerie Hubert Winter. Disponible en: https:/ /www.galeriewinter.at/site/assets / files/2278/abigailsolomon-godeau_sleeplessnights. pdf (Fecha de consulta: 27/02/2021).

SPERBER, Esther (2017). «The Poetics of Home: Between Psychological and Physical Structures». En No Place Like Home (cat. exp., comisaria Amina Kamien-Kazhdan), Jerusalén: The Israel Museum, pp. 15-24.

TAYLOR, Laurie (2011). Tracey Emin. In confidence with Laurie Taylor (entrevista). Reino Unido: Sky Arts, 50'. Disponible en: https://www.youtube.com/ watch?v=vSNXVjU_Tdo (Fecha de consulta: 27/02/2021).

Todorov, Tzvetan (2013). Elogio de lo cotidiano. Ensayo sobre la pintura holandesa del siglo XVII. Barcelona: Galaxia Gutemberg.

VAN Assche, Christine (2015). Mona Hatoum (cat. exp., comisaria Christine Van Assche). París: Centre Pompidou.

VIGUÉ, Joan y RICKETTS, Melissa (2007). La medicina en la pintura. El arte médico. Barcelona: Ars Medica.

Recibido el 29 de junio de 2020

Aceptado el 28 de febrero de 2021 BIBLID [1132-8231 (2021): 341-367] 